\title{
Germacrone Induces Apoptosis as Well as Protective Autophagy in Human Prostate Cancer Cells
}

This article was published in the following Dove Press journal:

Cancer Management and Research

\author{
Ziqiang Yu \\ Jiuping $X u$ \\ Mingfeng Shao \\ Jianan Zou
}

Department of Urology, The First Affiliated Hospital of Anhui University of Chinese Medicine, Hefei City, Anhui Province 23003I, People's Republic of China
Correspondence: Mingfeng Shao; Jianan Zou

Tel +8655I62850073

Email sssmmmfff@I26.com;

zjamnwk@I63.com
Background: Germacrone, a natural product isolated from the traditional Chinese medicine Rhizoma Curcuma, has been reported to exhibit antitumor activities in vitro. To further understand the antitumor mechanism of germacrone, we investigated the growth inhibitory effect of germacrone on the human prostate cancer cell lines PC-3 (androgen independent) and 22RV1 (androgen dependent).

Materials and Methods: Prostate cancer cells were cultured with different concentrations of germacrone, and cell viability was measured by MTT assay. The levels of proteins were measured by Western blotting. Cell apoptosis was assessed by flow cytometry. Images of autophagy-related protein staining were captured by fluorescence microscopy. Autophagic flux was assessed by detecting the LC3B-II level.

Results: Our results indicated that germacrone treatment significantly inhibited cell proliferation by inducing apoptosis in a dose-dependent manner, with IC50 values of $259 \mu \mathrm{M}$ for PC-3 cells and $396.9 \mu \mathrm{M}$ for $22 \mathrm{RV} 1$ cells. Germacrone-treated cells also exhibited induction of autophagy, as evidenced by elevated LC3B-II protein expression levels and punctuate patterns. Additionally, an autophagy inhibitor enhanced the growth inhibitory effect of germacrone. Moreover, the phosphorylation of Akt and mTOR was inhibited in germacrone-treated prostate cancer cells.

Conclusion: Germacrone induced apoptosis and autophagy in prostate cancer cells by inhibiting the Akt/mTOR signaling pathway. Germacrone treatment also led to the activation of protective autophagy. These findings suggest that germacrone may potentially contribute to the development of a new therapeutic agent for prostate cancer treatment.

Keywords: germacrone, prostate cancer cells, apoptosis, autophagy, Akt/mTOR

\section{Introduction}

Prostate cancer (PCa) has been reported as the most common cancer in men over 50 years old, and it is the second most frequent cause of cancer-related death in males worldwide. ${ }^{1,2} \mathrm{PCa}$ is initially dependent on androgen and is sensitive to androgen deprivation therapy. ${ }^{3}$ However, tumors become insensitive to androgen deprivation within two years. As a result, PCa can slowly progress to the high-risk aggressive phase. ${ }^{4}$ Both surgical therapies and chemotherapy treatments may cause serious side effects. 5,6 Therefore, the identification and development of novel remedies against prostate cancer are urgently needed. Recent studies have shown that traditional Chinese medicine is efficient in regulating tumor growth with low toxicity. ${ }^{7,8}$ Thus, finding new anti-prostate cancer agents derived from traditional Chinese medicine has aroused our interest.

Rhizoma Curcuma (Ezhu in Chinese) is usually used in traditional Chinese medicine for cancer treatment. ${ }^{9}$ The underlying mechanisms of Rhizoma Curcuma action in 
cancer treatment remain elusive and controversial. Germacrone (Figure 1) is a major bioactive constituent extracted from Rhizoma Curcuma. ${ }^{10}$ Recent studies have determined that germacrone exerts significant anticancer activity. Treatment of human hepatoma cells and breast cancer cells with germacrone results in cell cycle arrest and apoptosis. $^{11,12}$ Additionally, germacrone inhibits ER $\alpha$ mediated gene expression at the transcriptional level in breast cancer cells. ${ }^{13}$ Moreover, germacrone reverses adriamycin resistance in human chronic myelogenous leukemia cells. ${ }^{14}$ However, the effect of germacrone on prostate cancer cells has never been investigated.

Autophagy involves providing energy by degrading longlived proteins and damaged organelles. ${ }^{15}$ Autophagic cells are characterized by the formation of notable doublemembraned vesicles, known as autophagosomes. ${ }^{16}$ Since autophagy is an important intracellular mechanism in maintaining homeostasis maintenance and growth regulation, this process participates in many physiological processes and human diseases. ${ }^{17}$ The protective role of autophagy helps cancer cells obtain energy sources for rapid proliferation and to develop resistance against chemotherapy. ${ }^{18,19}$ Many bioactive compounds from plants have been shown to trigger autophagy in cancer cells. However, there are no reports on the effect of germacrone on autophagy in cancer cells.

The present study aimed to investigate the inhibitory effects and molecular mechanisms of germacrone in prostate cancer cells.

\section{Materials and Methods}

\section{Materials}

Germacrone (purity $>98 \%$ ) was bought from Shanghai YuanYe Biotechnology Co. 3-(4,5-Dimethylthiazol-2-yl)2,5-diphenyl-tetrazolium bromide (MTT) was bought from Bio Basic. Antibody against GAPDH was bought from Merck Millipore (Darmstadt, Germany). Antibodies against LC3B, mTOR, p-mTOR, Akt, and p-Akt were bought from Cell Signaling Technology (Danvers, MA). HRP-conjugated

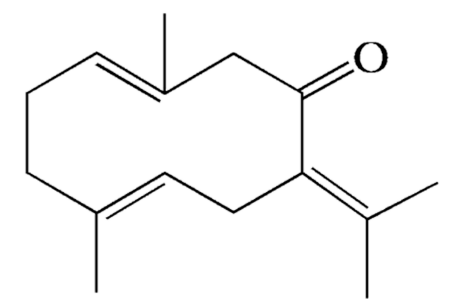

Figure I Chemical structure of germacrone. anti-rabbit antibody was bought from Promega (Madison, USA). An enhanced chemiluminescence (ECL) kit was bought from Biological Industries (Kibbutz Beit Haemek, Israel). Chloroquine and 3-methyladenine were purchased from Sigma Aldrich (St. Louis, MO). Goat anti-rabbit IgG H\&L was bought from Abcam (Cambridge, United Kingdom).

\section{Cell Culture}

Human prostate cancer cells (PC-3 and 22RV1 cells) were obtained from Shanghai Institutes for Biological Sciences, Chinese Academy of Sciences (Shanghai, China). The cells were cultured in the RPMI-1640 culture medium, 10\% fetal bovine serum containing $100 \mathrm{U} / \mathrm{mL}$ penicillin and $10 \mathrm{U} / \mathrm{mL}$ streptomycin at $37^{\circ} \mathrm{C}$ in an atmosphere of $5 \% \mathrm{CO}_{2}$.

\section{MTT Assay}

The inhibitory effects of germacrone on the viability of human prostate cancer cells were evaluated by MTT assay. The cells $\left(3 \times 10^{3}\right)$ were seeded into 96-well plates and left to adhere overnight. They were then treated with different concentrations $(30-480 \mu \mathrm{M})$ of germacrone for $48 \mathrm{~h}$ at $37^{\circ} \mathrm{C}$. Then, $20 \mu \mathrm{L}$ of MTT solution $(5 \mathrm{mg} / \mathrm{mL})$ was added and incubated at $37^{\circ} \mathrm{C}$ for $4 \mathrm{~h}$. After the MTT medium was aspirated, $150 \mu \mathrm{L}$ of DMSO was added to dissolve the insoluble formation product. The absorbance was determined at $490 \mathrm{~nm}$ using a spectrometer (Elx800, BioTek, Winooski, VT, USA).

\section{Detection of Apoptosis}

Cell apoptosis was assessed using an annexin V-FITC/PI apoptosis kit (Vazyme Biotech Co.). A total of 10,000 cells/well were seeded in 6-well plates and treated with germacrone for $48 \mathrm{~h}$. Then, the cells were harvested and washed twice in cold PBS and resuspended in $100 \mu \mathrm{L}$ binding buffer. The cell suspension was mixed with $5 \mu \mathrm{L}$ annexin V-FITC and $5 \mu \mathrm{L}$ PI staining solution for $10 \mathrm{~min}$ in the dark at room temperature. The cells were resuspended in $400 \mu \mathrm{L}$ binding buffer and were analyzed by flow cytometry (Becton Dickinson FACSCanto II, USA) within $1 \mathrm{~h}$.

\section{Immunofluorescence Analysis}

A total of 10,000 cells were seeded on glass bottom dishes and treated with germacrone for $48 \mathrm{~h}$. Then, the cells were fixed with $4 \%$ paraformaldehyde and permeabilized with $0.1 \%$ Triton X-100. Cells were incubated with a rabbit anti-LC3B antibody at $4^{\circ} \mathrm{C}$ overnight. Fluorescent secondary antibody was incubated for $1 \mathrm{~h}$ in the dark at room temperature. The 

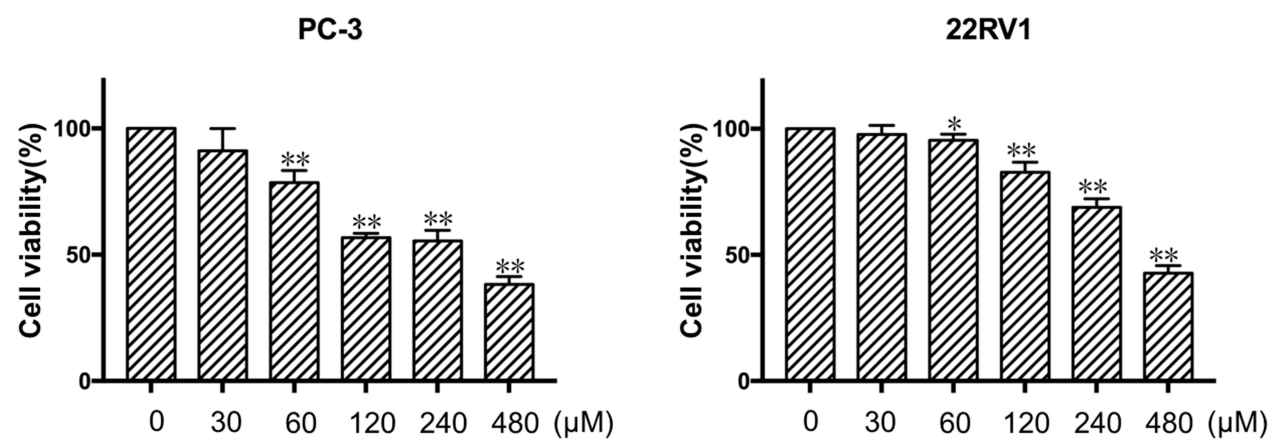

Figure 2 Effect of germacrone on the viability of human prostate cancer cells. PC-3 and $22 \mathrm{RVI}$ cells were incubated with various concentrations (30-480 $\mu \mathrm{M})$ of germacrone for $48 \mathrm{~h}$, after which the MTT assay was used to measure the cell proliferation rate. $* \mathrm{P}<0.05, * * \mathrm{P}<0.01$.

nuclei were stained with DAPI. Fluorescence images were captured by using a fluorescence microscope (Olympus TH4200, Tokyo, Japan).

\section{Western Blotting}

Prostate cancer cells were treated with germacrone, $50 \mu \mathrm{M}$ chloroquine (CQ) or $5 \mathrm{mM}$ 3-methyladeseven (3-MA) was added to the culture medium for the last $6 \mathrm{~h}$. After the cells were collected, the total proteins were extracted with RIPA buffer containing protease and phosphatase inhibitors on ice. The proteins were separated by SDS-PAGE and transferred to PVDF membranes. Then, the membrane was blocked with $5 \%$ BSA for $1 \mathrm{~h}$. Subsequently, the PVDF membrane was incubated with primary antibodies overnight at $4{ }^{\circ} \mathrm{C}$ and then incubated with an HRP-conjugated secondary antibody for $1 \mathrm{~h}$. Protein bands were visualized using an enhanced chemiluminescence (ECL) kit. Images of the protein bands were captured by chemiluminescent detection (LASmini 4000, GE Healthcare).

\section{Statistical Analysis}

One-way ANOVA was used between multiple groups. All data are expressed as the mean $\pm \mathrm{SD}$. ${ }^{*} \mathrm{P}<0.05$ and $* * \mathrm{P}<$ 0.01 were considered statistically significant.

\section{Results}

\section{Germacrone Decreased the Viability and Induced the Apoptosis of Prostate Cancer Cells}

Germacrone concentrations from 40 to $400 \mu \mathrm{M}$ exerted significant anticancer activities in different cancer cell lines in previous studies. ${ }^{11-14}$ Prostate cancer cells were incubated with or without germacrone at doses of 30, 60, 120,240 and $480 \mu \mathrm{M}$ for $48 \mathrm{~h}$ and were harvested for
MTT assay to measure viability. As shown in Figure 2, germacrone significantly inhibited the growth of prostate cancer cells in a dose-dependent manner, with IC50 values of $259 \mu \mathrm{M}$ for PC-3 cells and $396.9 \mu \mathrm{M}$ for $22 \mathrm{RV} 1$ cells.

To determine whether germacrone-induced cell death was related to apoptosis, annexin- $\mathrm{V}$ and PI double staining was performed to analyze the percentage of apoptotic cells by flow cytometry. The results revealed that after treatment with $240 \mu \mathrm{M}$ germacrone for $48 \mathrm{~h}$, the proportion of early and late apoptotic cells increased from $7.24 \%$ to $47.3 \%$ in PC-3 cells and from $5.27 \%$ to $47.48 \%$ in $22 \mathrm{RV} 1$ cells (Figure 3 ).

\section{Germacrone Induced Autophagy in Prostate Cancer Cells}

Apoptosis and autophagy are highly interactive. We next examined the effect of germacrone on autophagy. It is well known that LC3-II is regarded as an important marker of autophagy. ${ }^{20}$ Prostate cancer cells were treated with 120, 240 and $480 \mu \mathrm{M}$ germacrone for $48 \mathrm{~h}$. As shown in Figure 4A, a marked upregulation of LC3B-II expression was observed in a dose-dependent manner compared with the untreated cells. The diffusely expressed LC3 protein becomes concentrated and presents as puncta in the cytoplasm during the process of autophagy. ${ }^{21}$ In the present study, a significant increase in LC3B-II puncta formation was found in prostate cancer cells as soon as $48 \mathrm{~h}$ after treatment with $240 \mu \mathrm{M}$ germacrone (Figure 4B).

The accumulation of LC3-II protein is associated either with the increasing generation of autophagosomes or with the blockage of autophagosome and lysosome fusion processes. ${ }^{21}$ To determine whether germacrone induced autophagic flux, two autophagy inhibitors, 3-MA and CQ, which inhibit earlystage and late-stage autophagy, respectively, were used. As shown in Figure 5, the combination treatment with 
PC-3
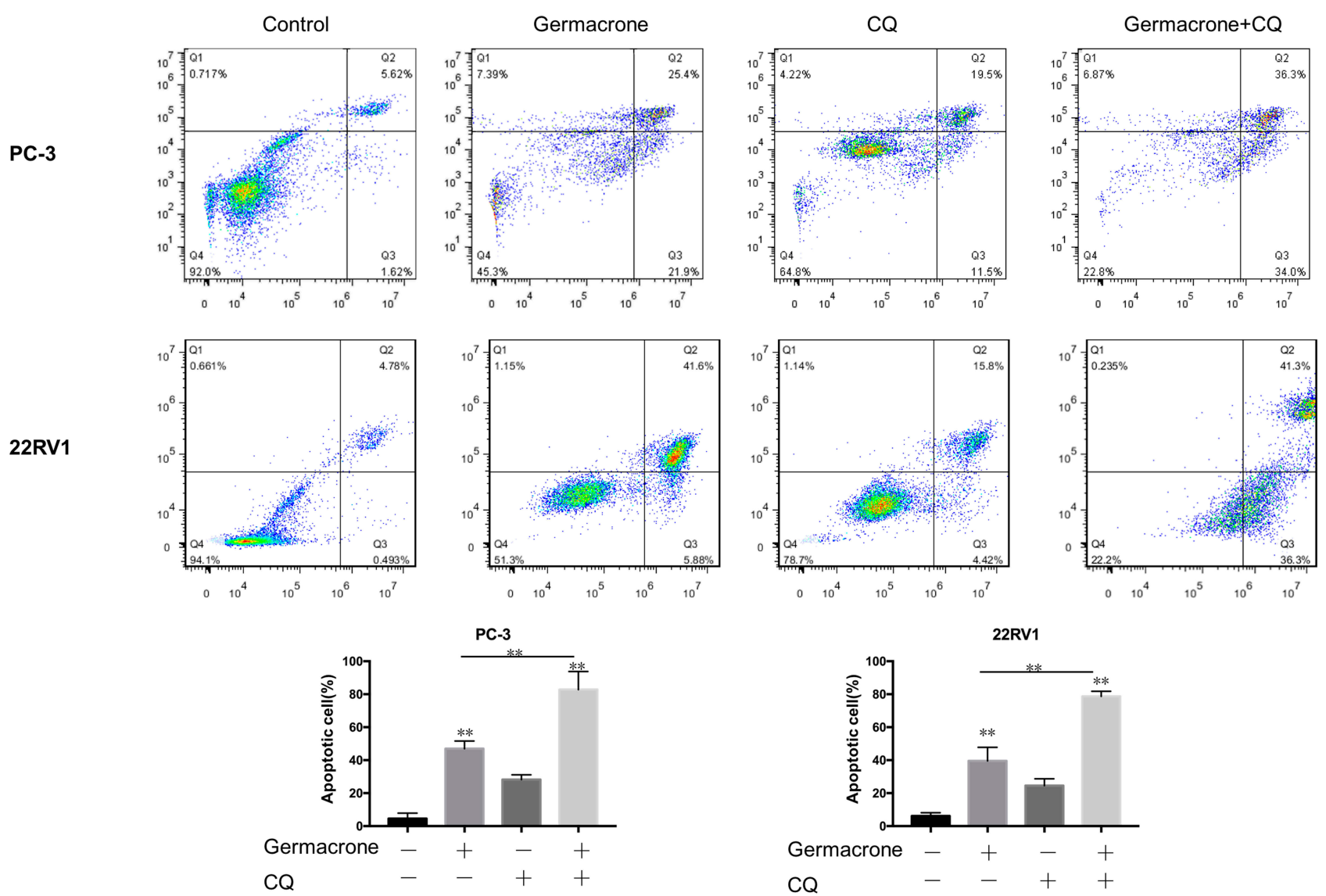

Figure 3 The apoptosis effect induced by germacrone alone or by germacrone cotreatment with an autophagy inhibitor. PC-3 and $22 \mathrm{RVI}$ cells were treated with $240 \mu \mathrm{M}$ germacrone for $48 \mathrm{~h}$, and $50 \mu \mathrm{M} \mathrm{CQ}$ was added to the culture medium for the last $6 \mathrm{~h}$. Cell apoptosis was assessed by flow cytometry with annexin V/PI staining. **P $<0.0 \mathrm{I}$.

germacrone and 3-MA exhibited less LC3B-II expression than that of germacrone treatment alone, and the combination treatment with germacrone and CQ resulted in higher LC3B-II expression than that with germacrone or $\mathrm{CQ}$ treatment alone, indicating that germacrone induced autophagy in PC-3 and 22RV1 cells.

\section{The Akt/mTOR Pathway Was Involved in Germacrone-Induced Apoptosis and Autophagy in Prostate Cancer Cells}

$\mathrm{Akt} / \mathrm{mTOR}$ is one of the most important signaling pathways in regulating survival and metabolism and has been proven to play a critical role in the regulation of apoptosis and autophagy. $^{22}$ Therefore, we speculated that germacrone might induce apoptosis and autophagy in prostate cancer cells via the Akt/mTOR signaling pathway. To verify this hypothesis, we used Western blot analysis to determine whether Akt/mTOR was inhibited in germacrone-treated prostate cancer cells. Prostate cancer cells were treated with 120, 240 and $480 \mu \mathrm{M}$ germacrone for $48 \mathrm{~h}$, and the levels of p-Akt and p-mTOR decreased in a dose-dependent manner (Figure 6). The results supported that germacrone induced both apoptosis and autophagy by inhibiting the $\mathrm{Akt} / \mathrm{mTOR}$ pathway in prostate cancer cells.

\section{Inhibiting Autophagy Promoted Germacrone-Induced Apoptosis}

The relationships between autophagy and apoptosis are complicated. To clarify the role of germacrone-induced autophagy in the antitumor process, the autophagy inhibitor CQ was used in the following experiments. We found that the addition of CQ enhanced germacrone inhibition of cell proliferation (Figure 7). Furthermore, annexin V/PI double staining showed that CQ promoted germacrone-induced apoptosis in prostate cancer cells (Figure 3 ). Compared with germacrone treatment alone, germacrone and CQ cotreatment increased the proportion of early and late apoptotic cells from $47.3 \%$ to $70.3 \%$ in PC-3 cells and from $47.48 \%$ to $77.6 \%$ in $22 \mathrm{RV} 1$ cells. Taken together, the results indicate that autophagy can protect prostate cancer cells from apoptosis in this case. 
A

PC-3
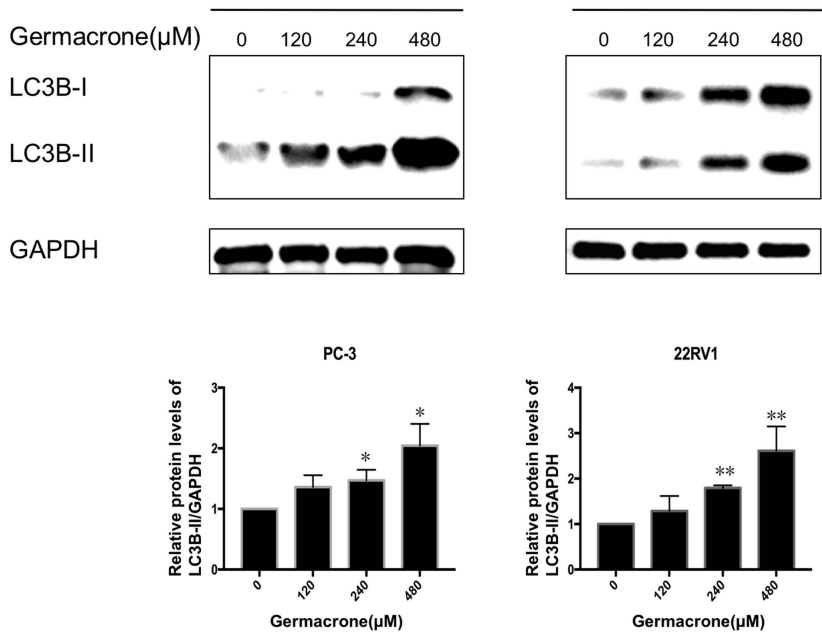

B

Control

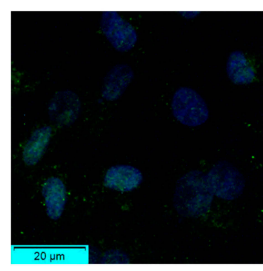

22RV1

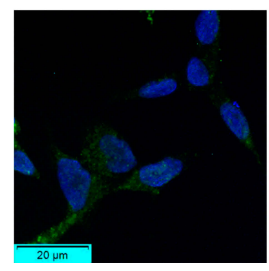

22RV1

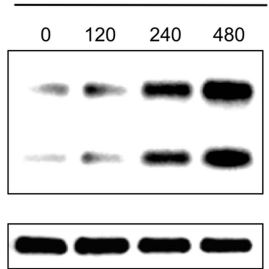

?

rmacrone $(\mu \mathrm{M})$

Germacrone
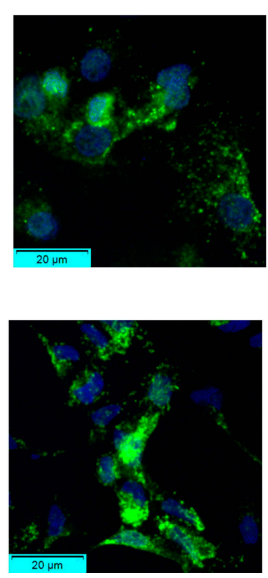

Figure 4 The effect of germacrone on the levels of LC3B in human prostate cancer cells. (A) PC-3 and 22RVI cells were treated with 120,240 and $480 \mu \mathrm{M}$ germacrone for $48 \mathrm{~h}$. The proteins of LC3B were detected by Western blotting. (B) PC-3 and $22 \mathrm{RVI}$ cells were treated with $240 \mu \mathrm{M}$ germacrone for $48 \mathrm{~h}$. After staining endogenous LC3 protein and nuclei with anti-LC3 antibody (FITC, green) and DAPI (blue), respectively, images of LC3 distribution were captured under a fluorescence microscope. $* \mathrm{P}<0.05$, $* * \mathrm{P}<0.01$.

\section{Discussion}

Natural herbal products are significant sources for the development of novel chemotherapeutics and have been used traditionally in various countries. Numerous studies indicate that these herbs have the ability to suppress tumor progression by regulating the proliferation, invasion or apoptosis of cancer cells. ${ }^{23}$ Germacrone, found in Rhizoma Curcuma essential oils, has been previously demonstrated to be a promising therapeutic agent against several types of cancer cells. ${ }^{11-14}$ However, the anticancer activities of germacrone against prostate cancer cells are not explicit.

In this study, we demonstrated that germacrone markedly inhibited the proliferation of prostate cancer cells. Apoptosis,
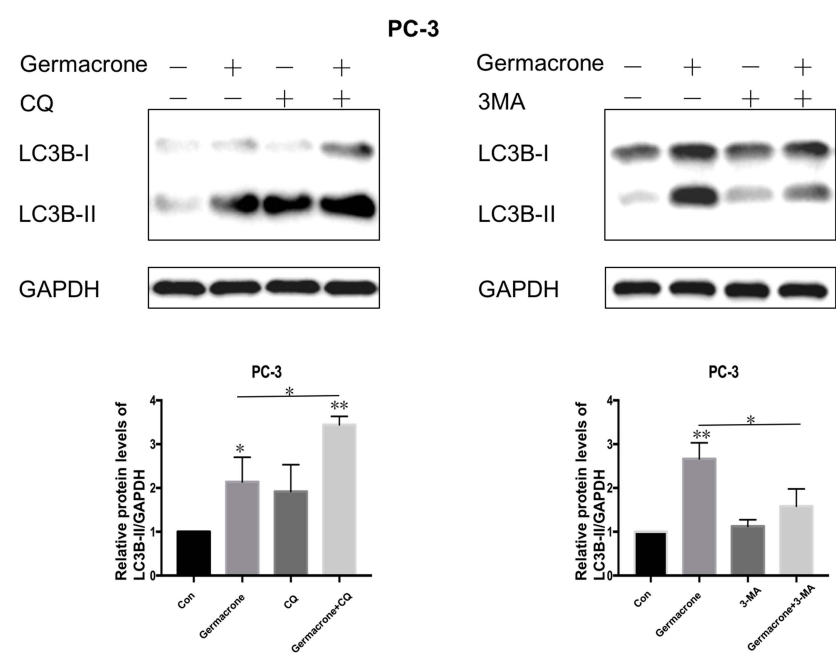

22RV1
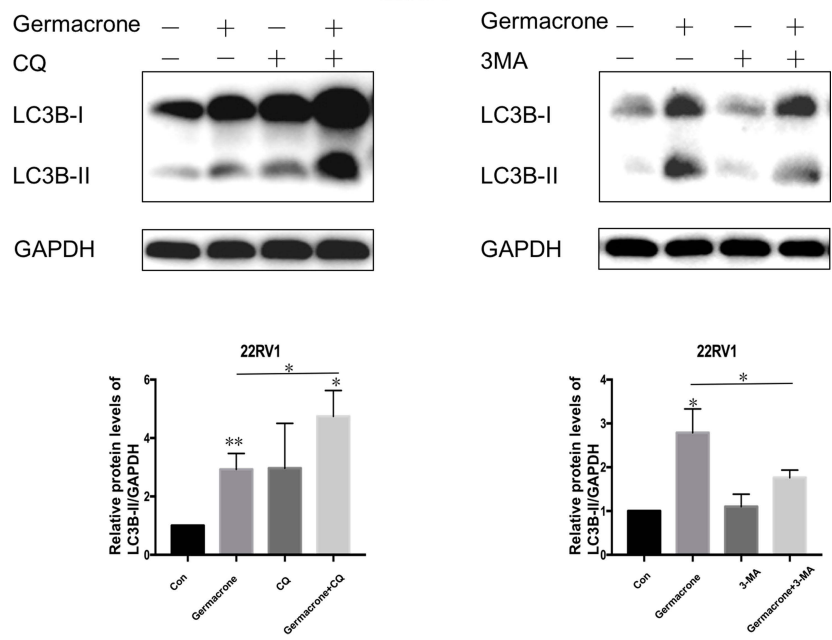

Figure 5 The effect of autophagy inhibitors on LC3B expression in germacronetreated human prostate cancer cells. PC-3 and 22RVI cells were treated with 240 $\mu \mathrm{M}$ germacrone for $48 \mathrm{~h}$, and $50 \mu \mathrm{M} \mathrm{CQ}$ or $5 \mathrm{mM} 3-\mathrm{MA}$ was added to the culture medium for the last $6 \mathrm{~h}$. The proteins of LC3B were detected by Western blotting. $* \mathrm{P}<0.05$, **P $<0.01$.

also called programmed cell death, plays a vital role in suppressing the growth of cancer cells. Amplified apoptosis leads to damage or death of cells and tissues. Therefore, the induction of apoptosis has been recognized as an efficient strategy for cancer treatment. ${ }^{24}$ Our data indicated that the percentages of early and late apoptotic cells were markedly increased following treatment with germacrone. In accordance with our findings, other researchers have reported that germacrone inhibits the growth of cancer cells through the induction of apoptosis..$^{11,12}$

Autophagy is an essential intracellular degradation mechanism to promote survival under stress conditions of starvation or growth factor withdrawal. Autophagy generates autophagosomes in the cytosol and can be estimated 


\section{PC-3}

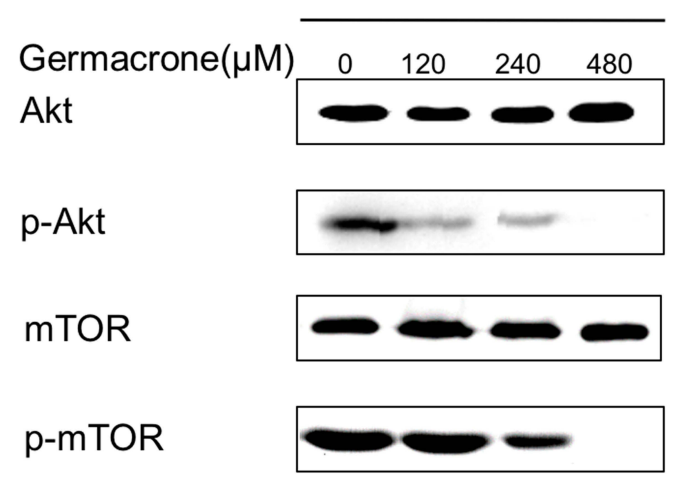

GAPDH

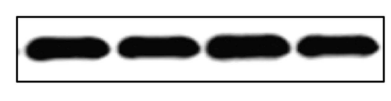

PC-3

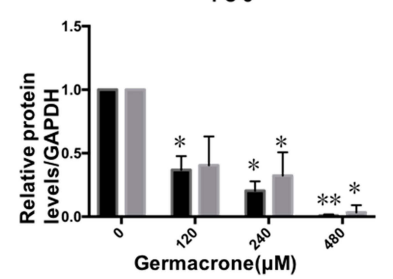

22RV1
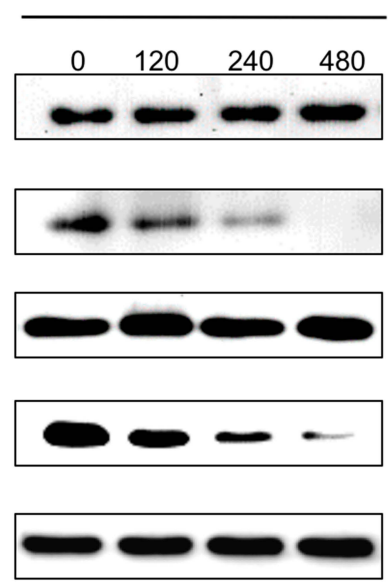

22RV1

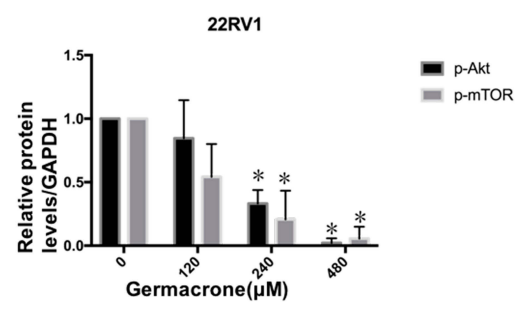

Figure 6 The inhibitory effect of germacrone on the Akt/mTOR signaling pathway. PC-3 and $22 \mathrm{RVI}$ cells were treated with I 20,240 and $480 \mu \mathrm{M}$ germacrone for $48 \mathrm{~h}$. The mTOR, $\mathrm{p}-\mathrm{mTOR}$, Akt, and $\mathrm{p}-\mathrm{Akt}$ protein levels were detected by Western blotting. $* \mathrm{P}<0.05, * * \mathrm{P}<0.01$.
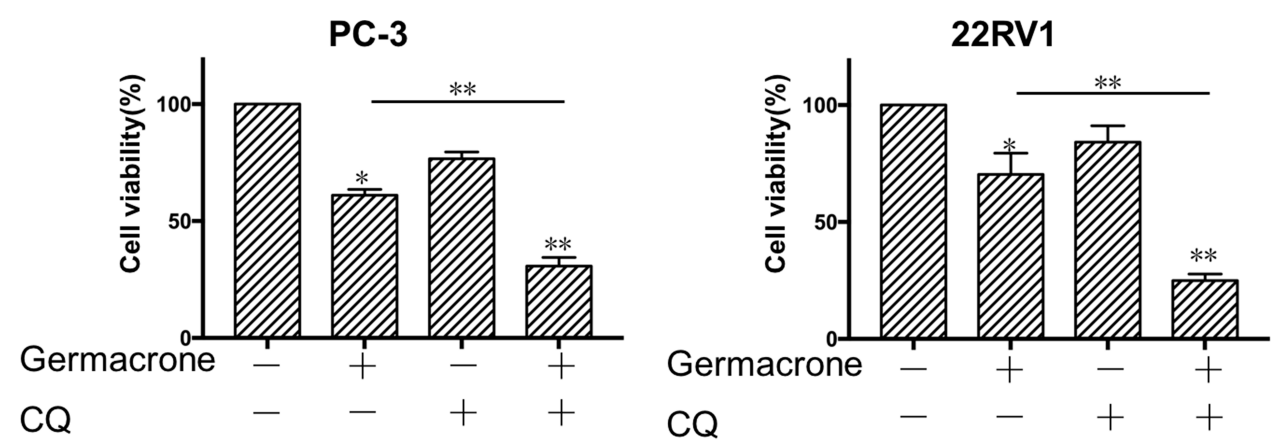

Figure 7 The inhibitory effect of germacrone on human prostate cancer cells was promoted by an autophagy inhibitor. PC-3 and $22 \mathrm{RVI}$ cells were treated with $240 \mu \mathrm{M}$ germacrone for $48 \mathrm{~h}$, and $50 \mu \mathrm{M} C \mathrm{CQ}$ was added to the culture medium for the last $6 \mathrm{~h}$. Cell viability was detected by MTT assay. $* \mathrm{P}<0.05$, $* * \mathrm{P}<0.0 \mathrm{l}$.

by detecting the expression of LC3-II. ${ }^{20}$ Our results showed that germacrone markedly elevated LC3B-II levels in a dose-dependent manner. Based on these results, the autophagy inhibitors 3-MA and CQ were used to check whether germacrone induced autophagy. As a result, germacrone-induced LC3B-II expression in prostate cancer cells was decreased by the addition of the early-stage autophagy inhibitor 3-MA and increased by the addition of the late-stage autophagy inhibitor CQ. These results demonstrated that germacrone induced autophagy in prostate cancer cells. Autophagosomes observed by electron microscopy are the morphological hallmark of autophagy, and the lack of electron microscopy data is one of the limitations of this study.

Apoptosis and autophagy can be induced by the same stimulus, but there is complex crosstalk between them. Autophagy has the ability to inhibit, delay or promote apoptosis. ${ }^{25-27}$ In the process of our study, we found that apoptosis was significantly increased with the inhibition of autophagy by $\mathrm{CQ}$. Compared with germacrone treatment alone, the combination treatment with CQ and germacrone resulted in decreased viability and increased apoptosis in prostate cancer cells. We hypothesized that germacrone induced apoptosis and autophagy simultaneously, whereas 
autophagy decreased prostate cancer cell susceptibility to germacrone-induced apoptosis. Autophagy functions as a cytoprotective factor in response to germacroneinduced apoptosis.

Increasing evidence indicates that autophagy and apoptosis share many common regulatory molecules. The Akt/ mTOR pathway, a well-known major regulatory signaling pathway in modulating cell proliferation, metabolism and survival, is very frequently dysregulated in the pathogenesis of human cancers. ${ }^{28}$ Therefore, targeting the Akt/ mTOR pathway is an attractive strategy for cancer prevention and treatment. Inhibition of the Akt/mTOR signaling pathway, which causes cell death, is associated with apoptosis and autophagy. ${ }^{29}$ Our data showed that germacrone inhibited the phosphorylation of both Akt and mTOR. The inhibitory effects of germacrone on prostate cancer cells may be correlated with the decrease in the phosphorylation of Akt and mTOR. These findings indicated that germacrone induced apoptosis and autophagy in prostate cancer cells by inhibiting the Akt/mTOR signaling pathway.

Taken together, this study demonstrated that germacrone inhibited the proliferation of human prostate cancer cells by inducing apoptosis. Germacrone treatment also led to the activation of protective autophagy. Inhibition of autophagy significantly enhanced the apoptosis-inducing ability. More importantly, the Akt/mTOR signaling pathway was inhibited by germacrone, suggesting that germacrone may serve as a promising active antitumor drug by direct regulation of the $\mathrm{Akt} / \mathrm{mTOR}$ pathway in prostate cancer cells. Due to the complicated metabolism of germacrone in vivo, further research will be necessary to explore its molecular mechanisms and to evaluate its anticancer activities in animal experiments. In addition, germacrone, as an Akt/mTOR inhibitor, needs to be exploited in combination with targeted therapies to improve prostate cancer clinical outcomes.

\section{Disclosure}

The authors declare no conflicts of interest.

\section{References}

1. Plata Bello A, Concepcion Masip T. Prostate cancer epidemiology. Arch Esp Urol. 2014;67(5):373-382.

2. Siegel RL, Miller KD, Jemal A. Cancer statistics. CA Cancer J Clin. 2018;68(1):7-34. doi:10.3322/caac.21442

3. Grossmann M, Cheung AS, Zajac JD. Androgens and prostate cancer; pathogenesis and deprivation therapy. Best Pract Res Clin Endocrinol Metab. 2013;27(4):603-616. doi:10.1016/j.beem.2013.05.001
4. Smith PC, Hobisch A, Lin DL, Culig Z, Keller ET. Interleukin-6 and prostate cancer progression. Cytokine Growth Factor Rev. 2001;12 (1):33-40. doi:10.1016/S1359-6101(00)00021-6

5. Keyes M, Crook J, Morton G, Vigneault E, Usmani N, Morris WJ. Treatment options for localized prostate cancer. Can Fam Physician. 2013;59(12):1269-1274.

6. Wang L, Martins-Green M. Pomegranate and its components as alternative treatment for prostate cancer. Int J Mol Sci. 2014;15 (9):14949-14966. doi:10.3390/ijms150914949

7. Han LT, Fang Y, Cao Y, et al. Triterpenoid saponin flaccidoside II from anemone flaccida triggers apoptosis of NF1-associated malignant peripheral nerve sheath tumors via the MAPK-HO-1 pathway. Onco Targets Ther. 2016;9:1969-1979. doi:10.2147/OTT.S95597

8. Feng M, Zhong LX, Zhan ZY, Huang ZH, Xiong JP. Resveratrol treatment inhibits proliferation of and induces apoptosis in human colon cancer cells. Med Sci Monit. 2016;22:1101-1108. doi:10.12659/MSM.897905

9. Bi YH, Zhang LH, Chen SJ, Ling QZ. Antitumor mechanisms of curcumae rhizoma based on network pharmacology. Evid Based Complement Alternat Med. 2018;2018:4509892. doi:10.1155/2018/4509892

10. Dang YY, Li XC, Zhang QW, Li SP, Wang YT. Preparative isolation and purification of six volatile compounds from essential oil of Curcuma wenyujin using high-performance centrifugal partition chromatography. J Sep Sci. 2010;33(11):1658-1664. doi:10.1002/ jssc. 200900453

11. Liu Y, Wang W, Fang B, et al. Anti-tumor effect of germacrone on human hepatoma cell lines through inducing G2/M cell cycle arrest and promoting apoptosis. Eur J Pharmacol. 2013;698(1-3):95-102. doi:10.1016/j.ejphar.2012.10.013

12. Zhong Z, Chen X, Tan W, et al. Germacrone inhibits the proliferation of breast cancer cell lines by inducing cell cycle arrest and promoting apoptosis. Eur J Pharmacol. 2011;667(1-3):50-55. doi:10.1016/j. ejphar.2011.03.041

13. Lim MS, Choung SY, Jeong KW. Germacrone inhibits estrogen receptor $\alpha$-mediated transcription in MCF-7 breast cancer cells. Phytother Res. 2016;30(12):2036-2043. doi:10.1002/ptr.5711

14. Pan J, Miao D, Chen L. Germacrone reverses adriamycin resistance in human chronic myelogenous leukemia K562/ADM cells by suppressing MDR1 gene/P-glycoprotein expression. Chem Biol Interact. 2018;288:32-37. doi:10.1016/j.cbi.2018.04.012

15. Yang Z, Klionsky DJ. Eaten alive: a history of macroautophagy. Nat Cell Biol. 2010;12(9):814-822. doi:10.1038/ncb0910-814

16. Klionsky DJ, Emr SD. Autophagy as a regulated pathway of cellular degradation. Science. 2000;290(5479):1717-1721. doi:10.1126/ science.290.5497.1717

17. Ravikumar B, Sarkar S, Davies JE, et al. Regulation of mammalian autophagy in physiology and pathophysiology. Physiol Rev. 2010;90 (4):1383-1435. doi:10.1152/physrev.00030.2009

18. Sato K, Tsuchihara K, Fujii S, et al. Autophagy is activated in colorectal cancer cells and contributes to the tolerance to nutrient deprivation. Cancer Res. 2007;67(20):9677-9684. doi:10.1158/00085472.CAN-07-1462

19. Peng X, Gong F, Chen Y, et al. Autophagy promotes paclitaxel resistance of cervical cancer cells: involvement of warburg effect activated hypoxia-induced factor 1-alpha-mediated signaling. Cell Death Dis. 2014;5(8):e1367. doi:10.1038/cddis.2014.297

20. Kabeya Y, Mizushima N, Ueno T, et al. LC3, a mammalian homologue of yeast Apg8p, is localized in autophagosome membranes after processing. EMBO J. 2000;19(21):5720-5728. doi:10.1093/ emboj/19.21.5720

21. Klionsky DJ, Abdelmohsen K, Abe A, et al. Guidelines for the use and interpretation of assays for monitoring autophagy. Autophagy. 2016;12(1):1-222.

22. Zhao GX, Pan H, Ouyang DY, He XH. The critical molecular interconnections in regulating apoptosis and autophagy. Ann Med. 2015;47(4):305-315. doi:10.3109/07853890.2015.1040831 
23. Catalani E, Proietti Serafini F, Zecchini S, Picchietti S, Fausto AM. Natural products from aquatic eukaryotic microorganisms for cancer therapy: perspectives on anti-tumour properties of ciliate bioactive molecules. Pharmacol Res. 2016;113(Pt A):409-420. doi:10.1016/j. phrs.2016.09.018

24. Marusyk A, Almendro V, Polyak K. Intra-tumour heterogeneity. A looking glass for cancer? Nat Rev Cancer. 2012;12(5):323-334. doi: $10.1038 / \mathrm{nrc} 3261$

25. Pan WR, Chen YL, Hsu HC, Chen WJ. Antimicrobial peptide GW-H1-induced apoptosis of human gastric cancer AGS cell line is enhanced by suppression of autophagy. Mol Cell Biochem. 2015;400 (1-2):77-86. doi:10.1007/s11010-014-2264-3

26. Jing Z, Sui X, Yao J, et al. SKF-96365 activates cytoprotective autophagy to delay apoptosis in colorectal cancer cells through inhibition of the calcium/CaMKII $\gamma /$ AKT-mediated pathway. Cancer Lett. 2016;372(2):226-238. doi:10.1016/j.canlet.2016.01.006
27. Hsin IL, Ou CC, Wu MF, et al. GMI, an immunomodulatory protein from ganoderma microsporum, potentiates cisplatin-induced apoptosis via autophagy in lung cancer cells. Mol Pharm. 2015;12 (5):1534-1543. doi:10.1021/mp500840z

28. Dou Q, Chen HN, Wang K, et al. Ivermectin induces cytostatic autophagy by blocking the PAK1/Akt axis in breast cancer. Cancer Res. 2016;76(15):4457-4469. doi:10.1158/0008-5472.CAN-15-2887

29. Wang F, Mao Y, You Q, Hua D, Cai D. Piperlongumine induces apoptosis and autophagy in human lung cancer cells through inhibition of PI3K/Akt/mTOR pathway. Int J Immunopathol Pharmacol. 2015;28(3):362-373. doi:10.1177/0394632015598849

\section{Publish your work in this journal}

Cancer Management and Research is an international, peer-reviewed open access journal focusing on cancer research and the optimal use of preventative and integrated treatment interventions to achieve improved outcomes, enhanced survival and quality of life for the cancer patient.
The manuscript management system is completely online and includes a very quick and fair peer-review system, which is all easy to use. Visit http://www.dovepress.com/testimonials.php to read real quotes from published authors. 